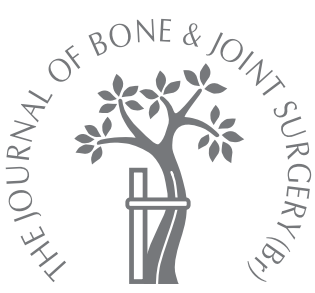

T. Akiyama, J. C. M. Clark, Y. Miki, P. F. M. Choong

From St Vincent's Hospital, Melbourne, Australia

\title{
The non-vascularised fibular graft
}

\author{
A SIMPLE AND SUCCESSFUL METHOD OF RECONSTRUCTION OF \\ THE PELVIC RING AFTER INTERNAL HEMIPELVECTOMY
}

Internal hemipelvectomy is a standard treatment for malignant tumours of the pelvis. Reconstruction using a non-vascularised fibular graft is relatively straightforward compared to other techniques. We describe the surgical and functional outcomes for a series of ten patients who underwent an internal hemipelvectomy (type I or I/IV) with reconstruction by a non-vascularised fibular graft between 1996 and 2009. A key prerequisite for this procedure was a preserved sciatic notch, confirmed pre-operatively on MRI.

Graft-host union was achieved in all patients with a single fibular graft, and in the lower graft where two grafts had been used. The mean time to union was 7.3 months (3 to 12). The upper graft did not unite in four of six cases where two grafts had been used. Seven patients were eventually able to walk without a stick. The mean post-operative Musculoskeletal Tumour Society score was $75.4 \%$ (16.7 to 96.7 ). There were no cases of deep post-operative infection. The mean pelvic shortening was $0.9 \mathrm{~cm}(0.2$ to 3.4$)$. Recurrent tumour occurred in three cases, and death from tumour-related disease occured in one.

Patients who need an internal hemipelvectomy will do well if their pelvic ring is reconstructed with a non-vascularised fibular graft. The complication rate is low, and they attain a good functional outcome.

- T. Akiyama, MD, PhD, Assistant Professor Department of Orthopaedic Surgery

Faculty of Medicine, The University of Tokyo, 7-3-1 Hongo, Bunkyo-ku, Tokyo 1130033, Japan.

J. C. M. Clark, MBBS, Orthopaedic Registrar

P. F. M. Choong, MBBS, MD, FRACS, FAOrthA, Director of Orthopaedics

Departments of Orthopaedics and Surgery

University of Melbourne, St Vincent's Hospital, 35 Victoria Parade, Fitzroy, Victoria 3065, Australia.

Y. Miki, MD, PhD, Orthopaedic Surgeon

Department of Orthopaedic Surgery

Teikyo University School of Medicine, 2-11-1 Kaga, Itabashiku, Tokyo 173-8605, Japan.

Correspondence should be sent to Professor P. F. M. Choong; email:sarcoma@bigpond.net.au

(c)2010 British Editorial Society of Bone and Joint Surgery doi:10.1302/0301-620X.92B7. $23497 \$ 2.00$

$J$ Bone Joint Surg [Br] 2010;92-B:999-1005. Received 24 September 2009; Accepted after revision 4 March 2010

VOL. 92-B, No. 7, JULY 2010 well. ${ }^{10}$ The aim of this study was to quantify the outcome measures specifically for patients undergoing NVFG reconstruction following a modified Enneking's type I or I/IV resection. $^{3,11}$

plications, such as injury to the iliac vessels, is high, ${ }^{1}$ and the need for lengthy rehabilitation is common. ${ }^{2}$ Consequently, patients need to be cared for by a multidisciplinary team. ${ }^{3}$

Limb-sparing internal hemipelvectomy, with reconstruction of the pelvis, is a standard treatment for malignant pelvic tumours, whenever wide resection margins can be achieved. ${ }^{4-6}$ Its advantages over amputation include preservation of the ability to walk and a decrease in the cosmetic and psychological side effects. ${ }^{3}$

Free vascularised fibular grafts (VFG) have been used to reconstruct pelvic ${ }^{7}$ and other large bony defects after resection of a tumour. ${ }^{8}$ Albeit largely successful, ${ }^{9}$ these require considerable time and microsurgical expertise to perform. There is currently no conclusive evidence to suggest that they perform better in pelvic reconstruction than a non-vascularised fibular graft (NVFG).

For reconstruction after excision of a tumour, the NVFG is a simpler, less timeconsuming technique than a VFG, and works

\section{Patients and Methods}

Between May 1996 and April 2009 we treated ten patients, seven men and three women, with a malignant pelvic tumour by internal hemipelvectomy and a NVFG. Four patients underwent a type I and six a type I/IV internal hemipelvectomy (Table I), according to our modification of Enneking's classification. ${ }^{3,11}$ Preservation of the sciatic notch, gluteal arteries and the sciatic nerve, as assessed by a pre-operative MR scan, ensured an adequate post-operative blood supply for the use of a gluteus maximus flap and functional innervation of the spared limb (Fig. 1). These MRI findings are key selection criteria for internal hemipelvectomy at our hospital.

The pathological diagnosis was chondrosarcoma in four cases, Ewing's sarcoma in three, and one each of osteosarcoma, malignant fibrous histiocytoma of soft parts, and a metastasis to bone of a malignant peripheral nerve sheath tumour. 
Table I. Details of the ten patients

\begin{tabular}{cllllll}
\hline Case & $\begin{array}{l}\text { Age } \\
\text { (yr) }\end{array}$ & Gender & Pathological diagnosis & Surgical stage & Surgical type & Type of bone fixation \\
\hline 1 & 28 & M & Osteosarcoma & IIB & T1 & Screw \\
2 & 51 & F & Chondrosarcoma & IB & T1 & Screw \\
3 & 44 & M & Chondrosarcoma & IB & T1/4 & Screw and plate \\
4 & 44 & M & Chondrosarcoma & IB & T1 & Screw \\
5 & 18 & F & Ewing's sarcoma & IIB & T1/4 & Screw and plate \\
6 & 18 & M & Ewing's sarcoma & IIB & T1 & Screw \\
7 & 49 & F & Chondrosarcoma & IB & T1/4 & Screw \\
8 & 51 & M & MPNST & IIB & T1/4 & Without device \\
9 & 77 & M & Soft part MFH & IIB & T1/4 & Screw \\
10 & 18 & M & Ewing's sarcoma & IIB & Screw
\end{tabular}

* MPNST, malignant peripheral nerve sheath tumour; MFH, malignant fibrous histiocytoma

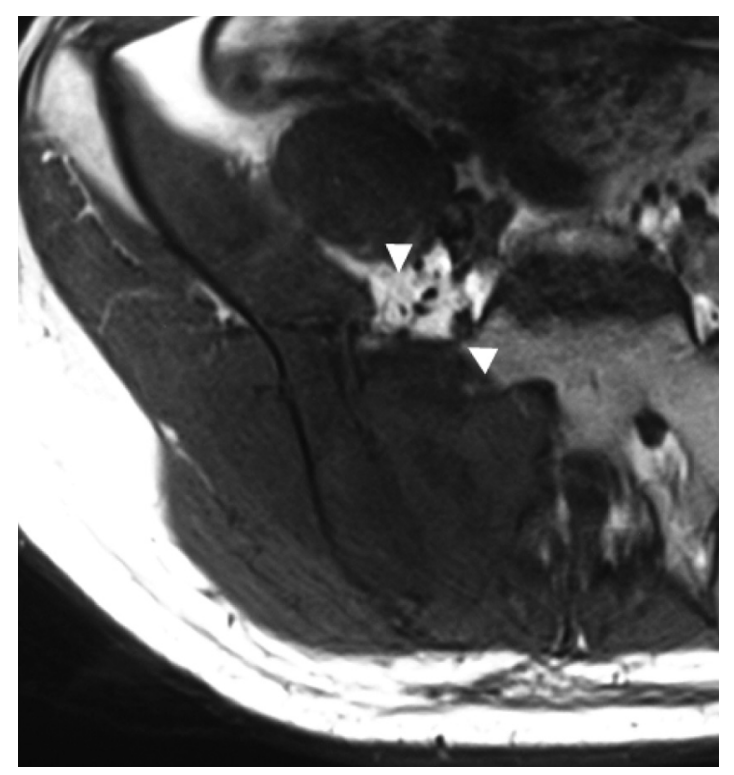

Fig. 1a

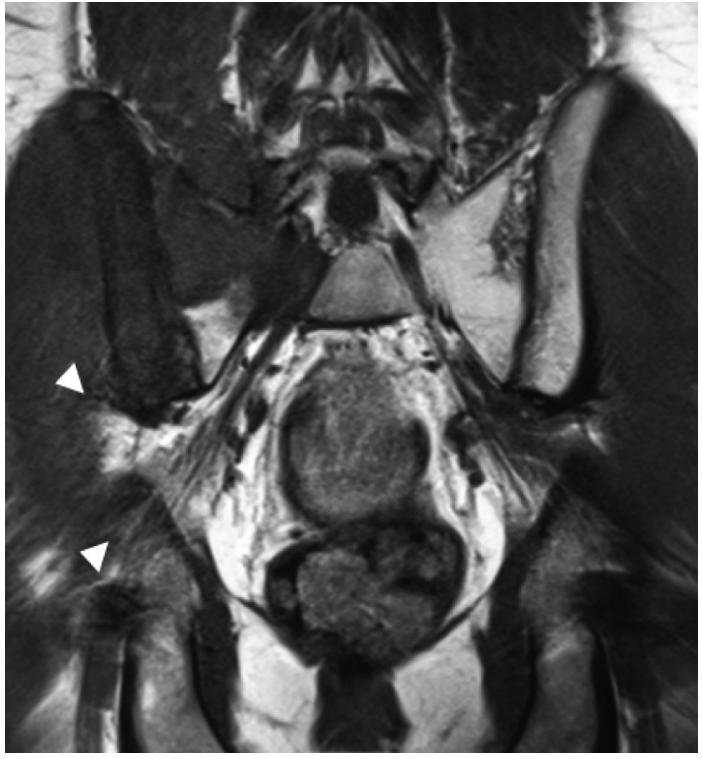

Fig. 1b

Figure 1a-Axial MR scan indicating the preservation of both superior and inferior gluteal arteries (arrows). Figure 1b-Coronal MR scan demonstrating the preservation of the sciatic notch and sciatic nerve (arrows).

The pelvic ring was reconstructed with double-barrelled fibular grafts in six cases and a single graft in four. The graft was fixed with cancellous screws in seven patients, cancellous screws and one-third tubular plates in two, and without metal in one (Table I). Patients with Ewing's sarcoma or osteosarcoma received neo-adjuvant chemotherapy. The patient with a malignant peripheral nerve sheath tumour had pre-operative radiotherapy (50.4 Gy). The mean postoperative follow-up was 29 months (5 to 56).

Surgical procedure. The operation was performed in a 'floppy lateral' position where there is decubitus, with side supports positioned to allow rolling of the patient by either $30^{\circ}$ anteriorly or posteriorly. The skin was incised from the caudal end of the sacroiliac joint, along the iliac crest to the anterior superior iliac spine and down to the midpoint of the thigh (Fig. 2). A gluteal flap was created and reflected posteriorly. In each case the superior and/or inferior gluteal artery and sciatic nerve were identified in the sciatic notch and preserved (Fig. 3). The fascia of the gluteus maximus was left attached to the skin to maintain the condition of the musculocutaneous flap (Fig. 3). After resection of the tumour, the same orthopaedic team harvested the ipsilateral fibula. An incision was made over the posterior aspect of the fibula which was divided distally $12 \mathrm{~cm}$ above the tip of the lateral malleolus. In each case the periosteum was preserved to maximise its potential for re-vascularisation and subsequent union. The resection bed was washed with 11 betadine, 11 chlorhexidine and more than 21 of saline. The number of fibular struts used and their method of fixation were determined by the intra-operative stability of the pelvis after resection, and by the width of the bony defect. Graft bone was used to bridge the sacrum and ilium without disturbing the sciatic nerve and the superior and/or inferior gluteal artery (Fig. 4). 


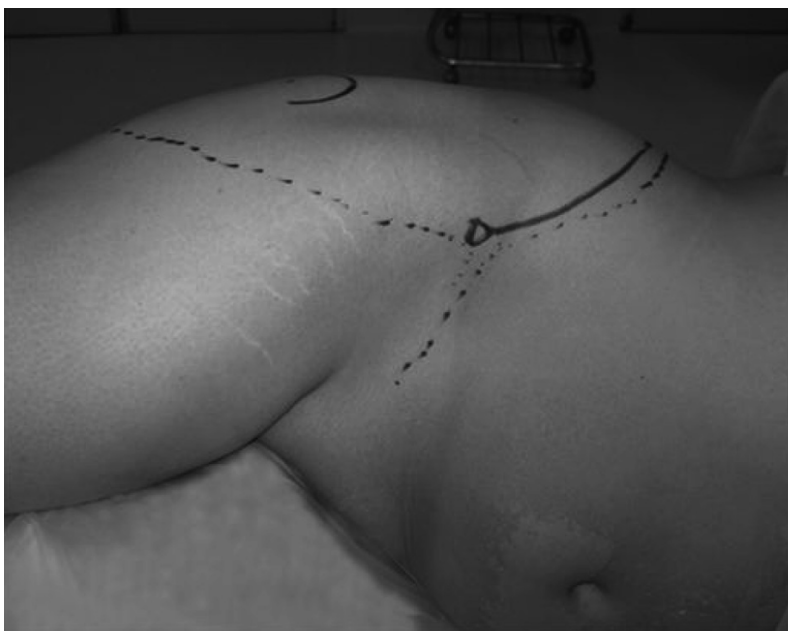

Fig. 2a

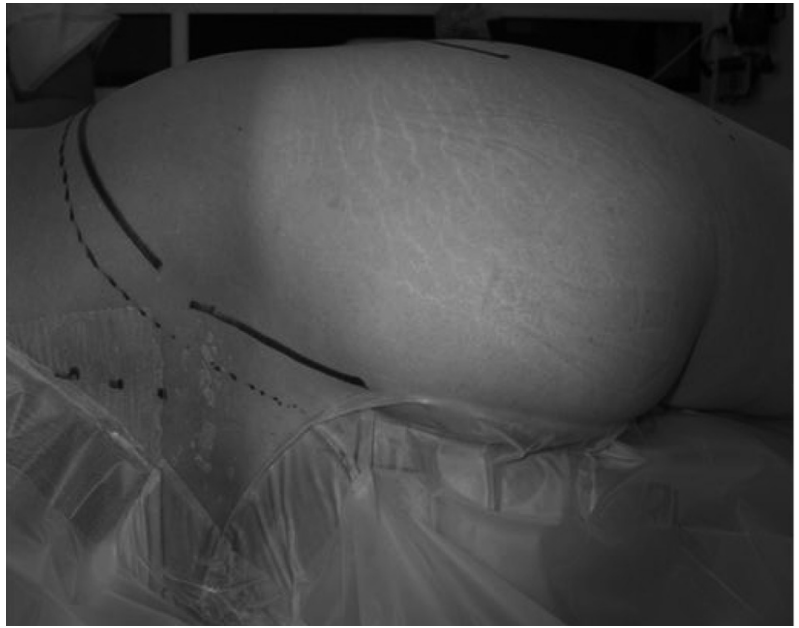

Fig. 2b

Photographs of the skin incision, demonstrated by the dashed line on a) anterior and b) posterior view. The solid line indicates the iliac crest and sacroiliac joint.

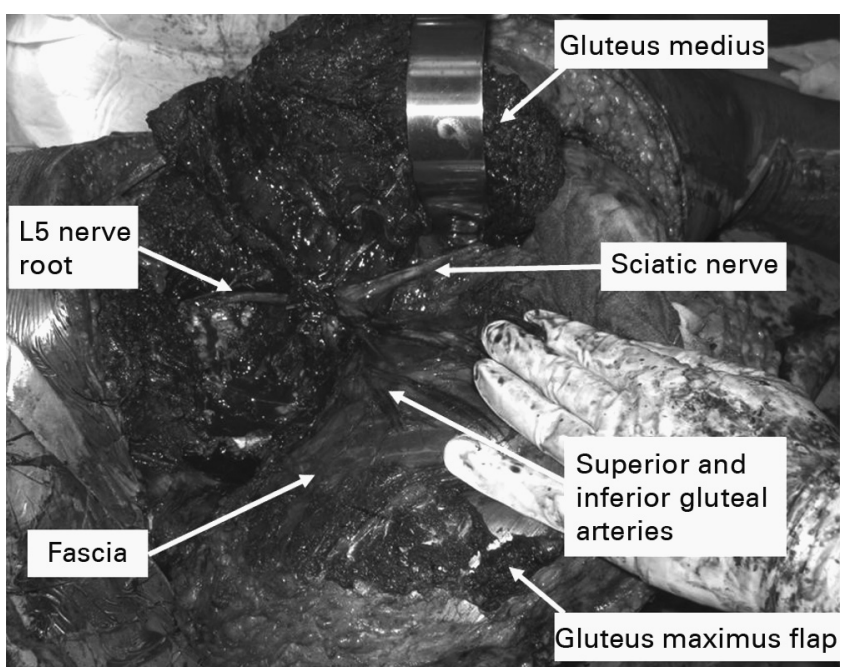

Fig. 3

Photograph of the surgical field after tumour resection. The sciatic nerve and superior and inferior gluteal arteries are successfully preserved. Note the fascia attachment to the gluteus maximus flap. This fascia maintains flap viability along with the gluteal vessels.

A fibre-glass hip spica in $30^{\circ}$ of flexion and abduction was applied just after wound closure. Partial weightbearing was permitted when signs of bone healing could be seen on radiographs or CT scans at around three to four months. Full weight-bearing was allowed when union was complete.

Recorded data. Post-operatively, the condition of the graft-host interface was monitored radiologically for evidence of union. Pelvic shortening was assessed at least six months post-operatively on an anteroposterior film by measuring the distance between a well-defined midline ana-

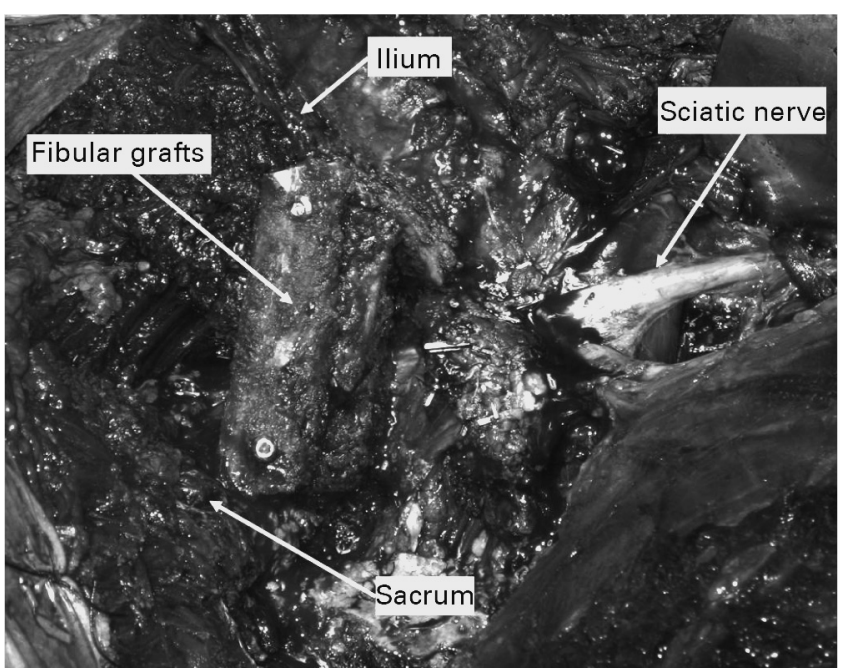

Fig. 4

Photograph of the graft, double-barrelled and fixed with cancellous screws.

tomical feature, usually the spinous process of the fifth lumbar vertebra, and the most inferior part of the teardrop on each side using the Centricity Picture Archiving and Communications System (GE Healthcare, Biosciences Corp, Piscataway, New Jersey). These landmarks were selected because they were the most consistently and clearly defined radiological features, and were not obscured by metalwork, fibular grafts or bony pathology. The difference in length between the resected and normal sides was calculated. The mean operating time, post-operative complications, time to graft-host union and functional evaluation were retrieved 


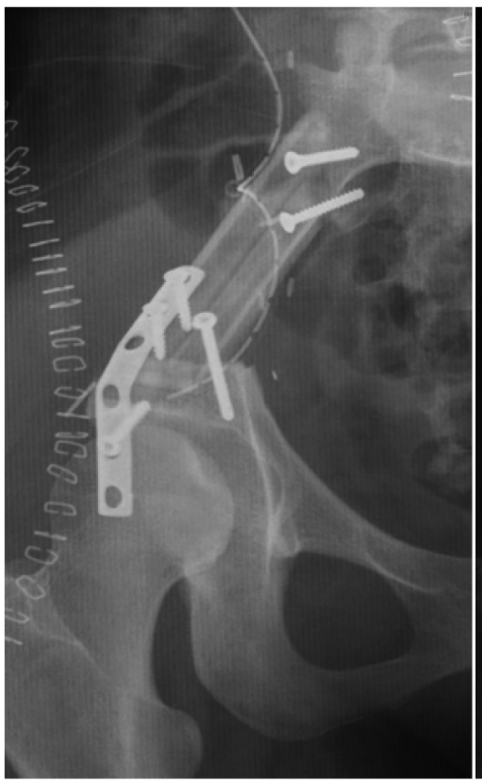

Post-operative

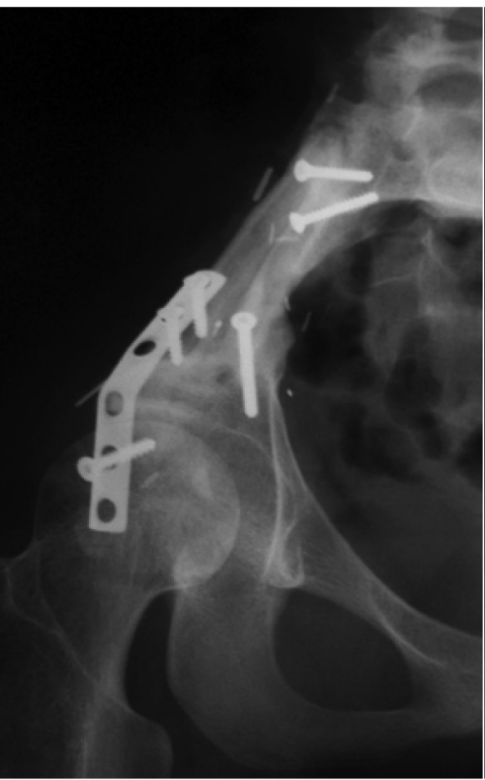

1 year

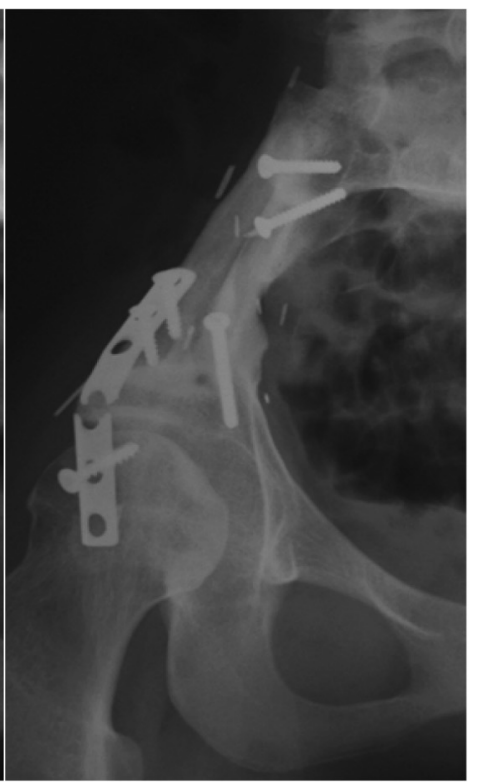

2 years 1 month

Fig. 5

Radiographs showing the chronological change of graft bone. Despite plate fracture, the lower non-vascularised fibular graft united.

Table II. Outcomes for ten patients who had a non-vascularised fibular graft following internal hemipelvectomy

\begin{tabular}{|c|c|c|c|c|c|c|c|c|c|}
\hline Case & $\begin{array}{l}\text { Follow-up } \\
\text { (mths) }\end{array}$ & $\begin{array}{l}\text { Lower/single strut } \\
\text { union (mths) }\end{array}$ & $\begin{array}{l}\text { Upper strut } \\
\text { union (mths) }\end{array}$ & $\begin{array}{l}\text { Op time } \\
\text { (hr and } \mathrm{min} \text { ) }\end{array}$ & $\begin{array}{l}\text { MSTS* score } \\
\text { (rating \%) }\end{array}$ & Prognosis $^{\dagger}$ & Recurrence & $\begin{array}{l}\text { Wound } \\
\text { necrosis }\end{array}$ & $\begin{array}{l}\text { Pelvic ring } \\
\text { shortening }(\mathrm{cm})\end{array}$ \\
\hline 1 & 12 & 5 & - & $N A^{\ddagger}$ & 16.7 & $\mathrm{DOD}^{+}$ & + & - & 0.0 \\
\hline 2 & 56 & 5 & - & 2 h $50 \mathrm{~min}$ & 56.7 & $\mathrm{CDF}^{\ddagger}$ & + & - & 0.0 \\
\hline 3 & 53 & 7 & Nonunion & $6 \mathrm{~h} 50 \mathrm{~min}$ & 80.0 & CDF & + & - & 0.6 \\
\hline 4 & 50 & 12 & - & NA & 96.7 & CDF & - & - & 2.1 \\
\hline 5 & 49 & 12 & 25 & $4 \mathrm{~h} 30 \mathrm{~min}$ & 96.7 & CDF & - & - & 0.8 \\
\hline 6 & 32 & 3 & 3 & 5 h $45 \mathrm{~min}$ & 90.0 & CDF & - & - & 1.7 \\
\hline 7 & 9 & 5 & Nonunion & 4 h $55 \mathrm{~min}$ & 90.0 & CDF & - & - & 0.2 \\
\hline 8 & 14 & 12 & - & $3 \mathrm{~h} 50 \mathrm{~min}$ & 80.0 & CDF & - & + & 3.4 \\
\hline 9 & 5 & 5 & Nonunion & 5 h $10 \mathrm{~min}$ & 90.0 & CDF & - & - & 0.2 \\
\hline 10 & 10 & 6 & Nonunion & $6 \mathrm{~h} 30 \mathrm{~min}$ & 60.0 & CDF & - & - & 0.0 \\
\hline Mean & 29.0 & 7.3 & & 4 h 56 min & 75.4 & $\begin{array}{l}\text { CDF } 9 / 10 \\
\text { DOD } 1 / 10\end{array}$ & $3 / 10$ & $1 / 10$ & 0.9 \\
\hline
\end{tabular}

* MSTS, musculoskeletal tumour society

† DOD, died of disease; CDF, complete disease-free survival

$¥$ NA, not available

from the clinical notes. Lower limb function was assessed using the Musculoskeletal tumour society score. ${ }^{12}$

\section{Results}

The outcomes are summarised in Table II. The mean operating time was four hours and 56 minutes ( 2 hours and 50 minutes to 6 hours and 30 minutes). Post-operative necrosis of the flap occurred in one case and was successfully treated by debridement. Deep infection was not seen.

Although at least one strut graft in each patient united, nonunion occurred in the upper strut in four of six patients in whom double struts were used (Table II). These nonunions were not treated surgically because the lower struts all consolidated sufficiently to allow full weight-bearing. This approach was validated by the lack of fracture of a graft during the follow-up period. The mean time to union for free NVFGs (lower/single struts) was 7.3 months (3 to 12). Fracture of a plate occurred in one case (Fig. 5), although this had minimal impact on the patient as the lower fibular graft united without fracture.

Of the whole group, seven patients had a minor degree of pelvic shortening (Table II) after a minimum of six months, but in no case did this require re-operation. The mean pelvic shortening was $0.9 \mathrm{~cm} \mathrm{(0.2} \mathrm{to} \mathrm{3.4).}$

The mean musculoskeletal tumour society score was $75.4 \%$ (16.7 to 96.7 ) (Table II). Six patients were able to 
walk without a stick, three needed a stick, and one was wheelchair bound because of ongoing pelvic pain. Local recurrance occurred in three patients. In one, local recurrance and metastasis was identified at 12 months postoperation. In the other two, local recurrance was identified at six and 12 months respectively. All were treated by reexcision.

\section{Discussion}

Hindquarter amputation was once the standard treatment for malignant pelvic tumours until Enneking began to advocate limb-sparing surgery. ${ }^{11,13}$ Internal hemipelvectomy was performed as early as the 1960s, albeit infrequently, but at that stage there were no reliable methods of reconstructing the pelvic ring. ${ }^{13}$ In the late 1970 s, several reports of internal hemipelvectomy described this procedure as an innovative surgical technique that attained reconstruction of the pelvic ring. ${ }^{14-17}$

The indications for internal hemipelvectomy are usually stricter than those for hindquarter amputation. ${ }^{18}$ In particular, type I and I/IV resections usually require an intact sciatic notch. Perhaps because of this, internal hemipelvectomy also has a significantly better rate of survival than hindquarter amputation, provided a wide margin of resection can be achieved. ${ }^{18}$ The purpose of internal hemipelvectomy is to achieve local and systemic control of the disease, ${ }^{18}$ whilst preserving the leg and the ability to walk. ${ }^{3}$

There are eight subtypes of internal hemipelvectomy, ${ }^{3}$ each of which requires a different method of reconstruction, although the best methods of doing this are still to be established. These techniques may involve the use of prostheses, allografts, autoclaved grafts, autograft-containing tumour treated with liquid nitrogen and free fibular grafts, either vascularised or non-vascularised. ${ }^{3,7,9,19-22}$ We have chosen to use NVFG specifically for T1 and T1/4 type resections.

Reconstruction with VFGs was first described in 1989, ${ }^{23}$ although the fate of the fibular grafts could not be determined as the patients died from metastatic disease. In 2005 and 2008 there were two reports of free vascularised, double-barrelled reconstruction. ${ }^{7,19}$ The main disadvantage of this procedure was the significantly increased operating time needed to carry out the microvascular anastomosis. ${ }^{19,24}$ Furthermore, it usually requires two teams of surgeons with the orthopaedic team performing the resection of the tumour and a plastic team managing the VFG. ${ }^{7,19}$ An NVFG can be undertaken by an orthopaedic team on its own.

Although each reconstruction technique has its individual advantages, it has generally been thought that most forms of pelvic reconstruction improve functional outcome. ${ }^{7,23}$ One study ${ }^{1}$ has shown that reconstruction is not an absolute requirement for maintaining function after iliosacral resection, although the patients had quite marked distortion of the pelvic ring and a secondary scoliosis. Such a degree of distortion and instability is likely to result in poor long-term function because of progressive spinal deformity, ${ }^{25}$ and instability of the posterior pelvic ring tends to cause pain and subluxation of the pubic symphysis. $^{26}$ Consequently, reconstruction of the pelvic ring is likely to be important for the preservation of function, although studies with longer follow-up are needed to confirm this.

The patients in our series had minimal pelvic shortening. This may be due to a number of factors, including the use of double struts for added early support, the low rate of metal failure and close attention to rehabilitation. The three patients who had pelvic shortening greater than the mean of $0.9 \mathrm{~cm}(2.1 \mathrm{~cm}, 1.7 \mathrm{~cm}$ and $3.4 \mathrm{~cm}$, respectively) had musculoskeletal tumour society percentage scores of $96.7 \%, 90.0 \%$ and $86.7 \%$, respectively, with no pelvic pain at two years; all three were eventually able to walk without aids. This surprisingly good function may be related to posterior stability combined with a small degree of medialisation of the centre of the hip, which reduces pelvic tilt when walking. ${ }^{1}$ Significant ongoing pelvic pain occurred in only three patients, and only one of these had any pelvic shortening $(0.6 \mathrm{~cm})$. This patient had generalised pelvic pain which was unlikely to be related to shortening, given that this usually occurs in the region of the pubic symphysis.

By contrast, Hillmann et $\mathrm{al}^{27}$ had two of 12 cases of reconstruction with a NVFG that needed re-operation for limb-length discrepancy.

As far as the time to union of the graft is concerned, evidence of bone bridging, where new bone forms at the junction between the graft and osteotomised bone, has been observed radiologically at a mean of 2.5 months (two to four) in a series of VFG reconstructions, although the time to achieve complete union, where complete continuity between the graft and host bone through callus formation, as occurred was not mentioned. ${ }^{7,19}$ We have shown complete radiological union in at least one graft after a mean of 7.3 months for our NVFGs. This is consistent with another series of NVFGs used for reconstruction in a range of anatomical sites, which showed primary union of 41 of 46 grafts within a median of 24 weeks. ${ }^{10}$

In our series, six patients could walk without assistance as soon as their grafts had united. Full weight-bearing was not allowed until the graft had completely united, which may account for the lack of significant pelvic shortening and pain around the pubis symphysis.

Overall, the upper/superior strut grafts in our series showed less propensity to unite, with delayed union in one patient at 25 months and nonunion in four of six patients. However, even with an isolated case of fracture of a plate, there was no significant impact on the position of the fibular graft, eventual graft union or pelvic shortening as demonstrated by serial imaging (Fig. 5). A united lower strut was sufficient for full weight-bearing. Despite the reduced rate of union in the upper struts, we feel that this doublestrut technique has a role to play in bridging large defects by providing additional stability to the pelvic ring, which is likely to facilitate union of the lower struts. ${ }^{28,29}$ 
One factor that may contribute to the successful rate of union of the NVFGs is the preservation of the periosteum of the fibular graft. Removal of the periosteum adversely affects callus formation and can delay or disrupt bone formation. ${ }^{30}$ Inserting the NVFG into the pelvic metaphysis means that new metaphyseal cortical bone can form by coalescence of endochondral trabecular bone, possibly through the inductive effects of graft periosteum. ${ }^{31}$ Maintenance of the blood supply to the gluteal flap may also help to revascularise the fibular graft through the preserved periosteum.

The absence of deep infection in our series may be partly due to the well-vascularised gluteal flap, but may also be the result of the shorter operating time needed to implant an NVFG. There is a clear association between long operative times and infection in pelvic resections ${ }^{32}$ and other surgical procedures. ${ }^{33,34}$ Internal hemipelvectomy and pelvic ring reconstruction with a VFG takes between nine and 12 hours, ${ }^{19}$ whereas our NVFGs ranged from two hours and 50 minutes to six hours and 50 minutes. Previously, the risk of deep infection in both hindquarter amputation and internal hemipelvectomy procedures was about $21 \%$; the infection rate in autograft cases was only $8.3 \% .{ }^{27}$ The individual risk of infection using free vascularised doublebarrelled grafts is reported to be $20 \%,{ }^{7}$ whereas we saw no deep infection in any of our cases.

Allograft reconstruction of iliac resections has given less favourable results. There is a higher overall complication rate and a higher infection rate for reconstruction using allograft rather than autograft. ${ }^{27}$ The functional scores are also relatively lower for allograft reconstruction. ${ }^{35}$

To the best of our knowledge there is only one other reported series of pelvic reconstruction using an NVFG. Hillmann et $\mathrm{al}^{27}$ reported 12 cases which they compared with reconstruction using an allograft or a pelvic prosthesis. Reconstruction with an NVFG performed better overall than the other methods in terms of function and complications. A comparison of union rate with our series was not possible because this was not reported. Nine of their 12 patients required additional surgery, two for deep infection, two for haematoma, two for limb-length discrepancy, two for metal removal and one for biopsy. In our series, the relative absence of re-operation for infection or technical complications may have been the result of stricter selection criteria, as reconstruction with a NVFG was only performed for type I and I/ IV resections. Consistency of selection would have improved surgical technique, reduced operating time and hence reduced graft failure and infection.

The mean musculoskeletal tumour society rating score overall was $75.4 \%$. It was $85.0 \%$ in those who had completed their post-operative rehabilitation, that is, excluding cases 1 and 10. These figures are comparable to those of VFG reconstruction at $75 \%,{ }^{7}$ and endoprosthetic reconstruction at $77 \% .^{36}$

Our patients also had a good outcome from their tumour, with low rates of local and distant recurrence.
Kawai et $\mathrm{al}^{18}$ achieved a five-year survival rate of $63.8 \%$ with a limb-sparing hemipelvectomy, and only $21 \%$ for hindquarter amputation. The rate of distant recurrence at five years of limb sparing and hindquarter amputation patients was $32.5 \%$ and $47.4 \%$ respectively. ${ }^{13}$ In our series, only one of the ten patients died of their tumour. Our local recurrence rate was $30 \%$ and our rate of metastasis was $10 \%$ at follow-up.

Overall, these results show that a NVFG can restore the stability of the pelvic ring after a type I or type I/IV resection and give a good functional result. This is probably the result of careful patient selection and a reduced operating time.

No benefits in any form have been received or will be received from a commercial party related directly or indirectly to the subject of this article.

\section{References}

1. Beadel GP, McLaughlin CE, Aljassir F, et al. Iliosacral resection for primary bone tumours: is pelvic reconstruction necessary? Clin Orthop 2005;438:22-9.

2. Beck LA, Einertson MJ, Winemiller MH, et al. Functional outcomes and quality of life after tumor-related hemipelvectomy. Phys Ther 2008;88:916-27.

3. Yuen A, Ek ET, Choong PF. Research: is resection of tumours involving the pelvic ring justified?:a review of 49 consecutive cases. Int Semin Surg Oncol 2005;2:9.

4. Choong PF, Sim FH. Limb-sparing surgery for bone tumors: new developments. Semin Surg Oncol 1997;13:64-9.

5. Bacci G, Longhi A, Versari M, et al. Prognostic factors for osteosarcoma of the extremity treated with neoadjuvant chemotherapy: 15-year experience in 789 patients treated at a single institution. Cancer 2006;106:1154-61.

6. Rougraff BT, Simon MA, KneisI JS, Greenberg DB, Mankin HJ. Limb salvage compared with amputation for osteosarcoma of the distal end of the femur: a longterm oncological, functional, and quality-of-life study. J Bone Joint Surg [Am] 1994;76-A:649-56.

7. Sakuraba $\mathbf{M}$, Kimita $\mathbf{Y}$, lida $\mathbf{H}$, et al. Pelvic ring reconstruction with the double-barrelled vascularized fibular free flap. Plast Reconstr Surg 2005;116:1340-5.

8. Eward WC, Kontogeorgakos V, Levin LS, Brigman BE. Free vascularized fibular reconstruction of large skeletal defects after tumor resection. Clin Orthop 2010;468:590-8.

9. Nagoya S, Usui M, Wada T, Yamashita T, Ishii S. Reconstruction and limb salvage using a free vascularised fibular graft for periacetabular malignant bone tumours. J Bone Joint Surg [Br]2000;82-B:1121-4.

10. Krieg AH, Hefti F. Reconstruction with non-vascularised fibular grafts after resection of bone tumours. J Bone Joint Surg [Br] 2007;89-B:215-21.

11. Enneking WF, Dunham WK. Resection and reconstruction for primary neoplasms involving the innominate bone. J Bone Joint Surg [Am] 1978;60-A:731-46.

12. Enneking WF, Dunham W, Gebhardt MC, Malawar M, Pritchard DJ. A system for the functional evaluation of reconstructive procedures after surgical treatment of tumors of the musculoskeletal system. Clin Orthop 1993;286:241-6.

13. Enneking WF. Local resection of malignant lesions of the hip and pelvis. $J$ Bone Joint Surg [Am] 1966;48-A:991-1007.

14. Eilber FR, Grant TT, Sakai D, Morton DL. Internal hemipelvectomy - excision of the hemipelvis with limb preservation: an alternative to hemipelvectomy. Cancer 1979;43:806-9

15. Erikson U, Hjelmstedt A. Limb-saving radical resection of chondrosarcoma of the pelvis. J Bone Joint Surg [Am] 1976;58-A:568-70.

16. Steel HH. Partial or complete resection of the hemipelvis: an alternative to hindquarter amputation for periacetabular chondrosarcoma of the pelvis. J Bone Joint Surg [Am] 1978;60-A:719-30.

17. Johnson JT. Reconstruction of the pelvic ring following tumor resection. J Bone Joint Surg [Am] 1978;60-A:747-51.

18. Kawai A, Healey JH, Boland PJ, et al. Prognostic factors for patients with sarcomas of the pelvic bones. Cancer 1998;82:851-9.

19. Chang DW, Fortin AJ, Oates SD, Lewis Vo. Reconstruction of the pelvic ring with vascularized double-strut fibular flap following internal hemipelvectomy. Plast Reconstr Surg 2008;121:1993-2000

20. Bell RS, Davis AM, Wunder JS, et al. Allograft reconstruction of the acetabulum after resection of stage-IIB sarcoma: intermediate-term results. J Bone Joint Surg [Am] 1997;79-A:1663-74 
21. Harrington KD. The use of hemipelvic allografts or autoclaved grafts for reconstruction after wide resection of malignant tumors of the pelvis. J Bone Joint Surg [Am] 1992;74-A:331-41.

22. Tsuchiya H, Wan SL, Sakayama $\mathbf{K}$, et al. Reconstruction using an autograft containing tumour treated by liquid nitrogen. J Bone Joint Surg [Br] 2005;87-B:218-25

23. O'Connor MI, Sim FH. Salvage of the limb in the treatment of malignant pelvic tumors. J Bone Joint Surg [Am] 1989;71-A:481-94.

24. Leung PC. Reconstruction of the pelvic ring after tumour resection. Int Orthop 1992;16:168-71.

25. Aebi M. The adult scoliosis. Eur Spine J 2005;14:925-48.

26. Chan K, Resnick D, Pathria M, Jacobson J. Pelvic instability after bone graft harvesting from posterior iliac crest: report of nine patients. Skeletal Radio/ 2001;30:278-81.

27. Hillmann A, Hoffmann C, Gosheger G, et al. Tumors of the pelvis: complications after reconstruction. Arch Orthop Trauma Surg 2003;123:340-4.

28. Stevenson S. Enhancement of fracture healing with autogenous and allogeneic bone grafts. Clin Orthop 1998;355(Suppl):239-46.

29. Yadav SS. Dual-fibular grafting for massive bone gaps in the lower extremity. J Bone Joint Surg [Am] 1990;72-A:486-94.
30. Kojimoto H, Yasui N, Goto T, Matsuda S, Shimomura Y. Bone lengthening in rabbits by callus distraction: the role of periosteum and endosteum. J Bone Joint Surg [Br] 1988:70-B:543-9.

31. Cadet ER, Gafni RI, McCarthy EF, et al. Mechanisms responsible for longitudinal growth of the cortex: coalescence of trabecular bone into cortical bone. J Bone Joint Surg $[A m] 2003 ; 85-A: 1739-48$

32. Ozaki T, Hillmann A, Bettin D, Wuisman P, Winkelmann W. High complication rates with pelvic allografts: experience of 22 sarcoma resections. Acta Orthop Scand 1996;67:333-8.

33. Nicolle LE, Huchcroft SA, Cruse PJ. Risk factors for surgical wound infection among the elderly. J Clin Epidemiol 1992;45:357-64.

34. Mangram AJ, Horan TC, Pearson ML, Silver LC, Jarvis WR. Guideline for prevention of surgical site infection, 1999: Hospital Infection Control Practices Advisory Committee. Infect Control Hosp Epidemiol 1999;20:250-78.

35. Schwameis $\mathbf{E}$, Dominkus $\mathbf{M}$, Krepler $\mathbf{P}$, et al. Reconstruction of the pelvis after tumor resection in children and adolescents. Clin Orthop 2002;402:220-35.

36. Tunn PU, Pomraenke D, Goerling U, Hohenberger P. Functional outcome after endoprosthetic limb-salvage therapy of primary bone tumours: a comparative analysis using the MSTS score, the TESS and the RNL index. Int Orthop 2008;32:619-25. 